\title{
Impact of Terrorism on KSE 100: Evidence from Karachi
}

\author{
SAMI UR REHMAN \\ Abdul Wali Khan University, Mardan \\ Samiurrahman40@gmail.com \\ QAZI SIKANDAR HAYAT \\ Lecuturer, Abdul Wali Khan University, Mardan \\ Qazi.hayat@awkum.edu.pk \\ GHAYYUR QADIR \\ Lecturer, Abdul Wali Khan University, Mardan \\ ghayyurqadir@awkum.edu.pk
}

\begin{abstract}
Terrorism is a critical issue throughout the world. In Pakistan, terrorism is one of the major obstacle in the growth of economy. The purpose of the study is to analyze the impact of terrorism in Karachi on the performance of KSE 100. Overall 27 big terrorist activities are considered in four years, ranging from 2011 to 2014. The performance of Karachi stock exchange is measured from the return of KSE 100 index. Moreover, the performance of KSE 100 index against terrorism in Karachi are analyzed through event study methodology and t-test. The result of the study shows that terrorism in Karachi has no significant impact on Karachi stock exchange 100 in all estimation windows. There is a little impact of some pre-event days on post-event days. But overall there is no significant result of terrorism in Karachi on KSE 100. The result highlights that the intensity of terrorist events is an important contributor in signifying the impact of terrorist events on KSE 100 index.
\end{abstract}

Keywords: KSE 100, Terrorism, Event study Methodology, Global Terrorism Data Base (GTD)

\section{Introduction}

The word terrorism is initially heard in the midst of the French revolution, in 1700. Terrorism has been defined as planned and deliberately done murder (Lila Perl). Many research studies have identified the impact of terrorism on different sectors and financial markets. The impact of terrorism is a terrible risk. Terrorism may have great effect on everyone's life, either directly or indirectly. Many economies, like Pakistan, Iran, Afghanistan, Syria, Jordan, Kuwait, Yemen and US are under serious constraint due to terrorism (Aurangzeb \& Dilawar., 2012). Terrorism is a critical issue throughout the world. Like other issues in Pakistan, terrorism is one of the major obstacles in the growth of economy, which hits almost every sector of the economy. Pakistan is facing nonstop terrorism and citizens are at risk. Due to this big menace, the foreign investors are losing 
their confidence in the financial markets of Pakistan. Infrastructure is almost damaged. The effect of terrorism attacks adversely affects FDI and increase the withdrawal of portfolio investment from the country (Gul et al., 2010). Terrorism is one of the major issues in Pakistan. Over the years, the terrorist activities are increasing in Pakistan. According to the ranking by the Institute of Economics and Peace, Pakistan has been placed at number three in terms of biggest terrorism affected countries (Hassan \& Hashmi., 2015). Terrorist activities caused to reduce the investments and inflows of capital in the country. Sometimes it shocks the whole economy sharply and forces to close the stock exchanges and other financial markets. The US stock market got close after 9/11 terrorist attacks for few days, that was a big shock for industries and businesses. A decline was observed in stock market after 9/11 attacks on World Trade Center. The decline in the stocks of tourism, airline and insurance was too much. The increase in variance of the stock market increased uncertainty in capital and ultimately affect negatively the return of stocks (Najaf et al., 2015).

Karachi is a city where 18 million peoples are living and it contributes 42 percent in GDP of Pakistan. Unfortunately, it is overabundant with terrorist activities including target killing and bomb blasts, and has been full of political, sectarian, and terrorist group violence for years. It is the big city of Pakistan which is considered a business hub of the country, but its actual contribution in the GDP is less than expected which is because of unsatisfactory circumstances. Terrorist activities in Karachi hit tourism industry, Hotel industry, manufacturing, transportation, and trade. Crucial factors of Karachi such as target killing, Taliban attacks, immigrants, political instability push back the contribution of industries in the economy. All these factors combined with "war-on-terror" downturn the business activities in Karachi, which leads to affect the financial markets in the country (Gul et al., 2005). Terrorist activities might be a reason to generate the short term unfavorable reaction in financial markets (Chen \& Siems, 2004). This specific study finds the significant relationship of terrorist events in Karachi on Karachi stock exchange. The research will contribute to the literature of finance by exploring the investor behavior before the event and after the event in Karachi by using the event methodology.

\section{Literature Review}

The literature about the impact of terrorism on financial markets is very limited. Most of the research focuses on the impact of very limited terrorist events and particularly on 9/11. Research study on the impact of terrorism on stock exchange gains much concentration after the deadly attacks of $9 / 11$ on World Trade center and Pentagon. Where 3000 people were lost their lives and many leaves injured (Washington post 2001). In the aftermath of $9 / 11$, investors lost their confidence across national boundaries with the contingent effect (Johnston \& Nedelscu., 2006). The 11 September 2001 attacks mainly affected the major industries and turn down the overall demand, generated by the loss in confidence of investors about the economy and its impact on returns. After the 9/11 attacks, impact of other major terrorist incidents on stock, like Madrid and London bomb attacks are investigated. The impact of these events on stock markets of Barcelona, Madrid, Valencia and London are investigated. 
The study confirmed a significant negative impact of the attacks on all these stock exchanges (Kollias, Papadamou \& Stagiannish., 2011). Terrorism in Pakistan is a big issue from last few years. According to a report, more than 40,000 peoples, includes security personals have lost their lives. Terrorism hit badly the financial market of Pakistan. The news headline (2007) of Benazir Butto assassination attack confirms that the drop in the index is caused only by mega terrorist attacks besides the rest of the attacks. There are other Political and economic reasons which might drop the index points (Dawn News 2008). The attack 2007 of the Benazir Bhutto assassination caused greater violence and destruction in the country. It provoked her followers, which caused major property destruction and totally disturbed the law and order situation of the country. The attack caused a rapid decline in KSE 100 index, followed by an immediate recovery of the market (Abbas, Ahmed, Mahmood \& Hassan, 2014). Abbas et al (2014) shows statistically significant impact of three major terrorist events, including 2007 attack of Benazir butto assassination, 2008 attack of Merit hotel and2010 attack of Darra Adamkhel on KSE 100 index, using event methodology.

The 2007 assassination of Benazir button and the Merriott hotel attack showed negatively impact on investments at the Karachi stock exchange. The result concludes that greater the violence created by terrorist attacks, greater would be its impact on the KSE. The study suggests that attack on special person or by some political leader has more negative impact on capital market as compared to attacks on civilians. Najaf, Iqbal. \& Shah, (2015) research Study concludes short term negatively significant impact, after investigating the impact of five terrorism and political events on KSE. They researchers argue in their study that the political and terrorism activities have negatively significant impact in the short run. But in the long run the impact is insignificant and positive. The authors used the T-statistics and event window for their research methodology. Basher, Haq \& Gillani (2013) investigate a negative relation between terrorist activities and Karachi stock exchange 100 indexes by using evidence from KSE. The researchers used ARCH methodology model. They argue that there is a highly significant relationship between bomb blasts and KSE. The terrorist attacks on some political leader create more violence and fear than the attack on civilians which ultimately effect stock trading. They conclude that terrorist attack in the capital city has more undesirable impact on financial markets as compare to other cites (Abbas et al, 2014).

Keeping in view the importance of PSX, which is located in Karachi, the study investigated the impact of Terrorism in Karachi on KSE 100. On the basis of given variables, the study considered only two hypotheses.

- H0: there is no association between terrorism in Karachi and KSE 100.

\section{Methodology}

- H1: There is an association between terrorism in Karachi and KSE 100.

Event Study methodology is used for this research study. The study considered those terrorist events in Karachi which have been occurred in 2011 to 2014 on the basis of defined criteria. The terrorist events which cause as a result at least 5 numbers of casualties, or any specific attack on a political leader or on a business man are considered 
for the study. Terrorist events which have maximum injuries are also considered for the study. A total of 27 terrorist attacks are identified for the study. The study take KSE 100 index return of 15 days before the event (pre-event) and 15 days after the event (postevent) individually of each terrorist event. T-statistics tests are used to find the mean of the population. The t-test is a statistical test which measures the difference in units of standard deviation, between an actual or observed sample statistic and its hypothesized population. It compares the calculated t-value of a population to a critical value or tabulated value on the t-distribution with df (n-1) to determine whether the difference is statistically significant between the hypothesized and estimated values of a population, or not. T-test values in this study states that whether terrorism in Karachi cause any change in stock trading or not. The $t$ value is considered 2.0 for defined population. Tests which have $\mathrm{T}$ value above than 2.0 and two tails $\mathrm{P}$-value is less than 0.05 are considered statistically significant. To test null hypothesis, we check $\mathrm{P}$ value. T-test values and $\mathrm{P}$ values are going arm by arm. $\mathrm{P}$ value states that how much the null hypothesis argument is true. It supports that how much your data is aligning with null hypothesis. High $\mathrm{P}$ values $(\mathrm{P}>0.05)$ states that null hypothesis is true while Low $\mathrm{P}$ values $(\mathrm{P}<0.05)$ states that our data is unlikely with a true null hypothesis. Higher $\mathrm{P}$ values suggested that our sample provides enough evidence to accept the null hypothesis for the entire population. Technically, a $\mathrm{P}$ value is the probability of obtaining a least effect as compare to extreme effect, as the one in our sample data and assuming the truth of the null hypothesis. Insignificant tests, which have high $\mathrm{P}$ values and Low t-test values, showed that there is no significant change in the indices during and after terrorist activity. The study considers all those tests significant; whose P-value two tails is less than 0.05 . To show, whether the difference between the means of the populations are statistically significant or not, we check the means of all rows (pre-event and post-event windows returns) and compare the p-value of ANOVA test to our significance level (0.05) to assess the null hypothesis. The null hypothesis states that the population means are all equal i.e. $(\mu 1=\mu 2)$ with a significant level of 0.05 . A 0.05 level of significance indicates a risk of 5\% concluding that a difference exists between the means of the population when there is no actual difference.

\section{Analysis and Results}

Table No: 1

\begin{tabular}{|llll|}
\hline Pre event-days & Post-event days & T-test values & P value two tail test \\
\hline-1 & 1 & -0.163560183 & 0.871506121 \\
-1 & 2 & 1.454828039 & 0.159229762 \\
& & & \\
-1 & 3 & 0.436549614 & 0.666508773 \\
-1 & 4 & 1.572594321 & 0.129469268 \\
-1 & 5 & 1.421896013 & 0.168476205 \\
-1 & 6 & 1.131993532 & 0.269301569 \\
-1 & 7 & 0.095618412 & 0.924651876 \\
\hline
\end{tabular}




\begin{tabular}{|c|c|c|c|}
\hline-1 & 8 & 0.508989728 & 0.615607815 \\
\hline-1 & 9 & 1.062784094 & 0.298911905 \\
\hline-1 & 10 & -0.239923791 & 0.812514739 \\
\hline-1 & 11 & 1.26217873 & 0.219533631 \\
\hline-1 & 12 & 0.815752994 & 0.423009489 \\
\hline-1 & 13 & 0.812657006 & 0.424747019 \\
\hline-1 & 14 & 1.505102923 & 0.14590801 \\
\hline-1 & 15 & 1.264561814 & 0.21869282 \\
\hline-2 & 1 & -1.693987393 & 0.103768756 \\
\hline-2 & 2 & -0.905183326 & 0.37475313 \\
\hline-2 & 3 & -1.394837154 & 0.176390995 \\
\hline-2 & 4 & -0.498855002 & 0.622619261 \\
\hline-2 & 5 & -0.746750952 & 0.462779718 \\
\hline-2 & 6 & -0.335303665 & 0.740435139 \\
\hline-2 & 7 & -2.168969104 & $0.04067081 *$ \\
\hline-2 & 8 & -1.540691217 & 0.137038712 \\
\hline-2 & 9 & -0.695125291 & 0.493940393 \\
\hline-2 & 10 & -2.139394132 & $0.043243427 *$ \\
\hline-2 & 11 & -0.968213442 & 0.343009646 \\
\hline-2 & 12 & -0.885528008 & 0.385036769 \\
\hline-2 & 13 & -1.175553355 & 0.251799293 \\
\hline-2 & 14 & -0.434515713 & 0.667963381 \\
\hline-2 & 15 & -1.126538596 & 0.271554677 \\
\hline
\end{tabular}

In above Table No: 1 of column 3 (t-test values), we find that pre-event day -2 and post-event day 7 and day 10, t-values and $\mathrm{P}$ values are significant $(\mathrm{t}=-2.168969104$, $\mathrm{t}=-2.139394132$ and $\mathrm{P}=0.04067081, \mathrm{P}=0.043243427)$. It means that there is a significant change in their population means. We checked that majority returns were trading upward, before 2 days the events but stock trading was decline in post-event period.

Table No: 2

\begin{tabular}{|llll|}
\hline Pre event-days & Post-event days & T-test values & P value two tail test \\
\hline-3 & 1 & -1.356962688 & 0.187962185 \\
-3 & 2 & -0.354944843 & 0.725865032 \\
-3 & 3 & -1.180388926 & 0.24990969 \\
-3 & 4 & -0.056310497 & 0.955580785 \\
-3 & 5 & -0.316001007 & 0.754851563 \\
-3 & 6 & 0.087020995 & 0.931408011 \\
-3 & 7 & -1.619907402 & 0.118883789 \\
-3 & 8 & -1.110720939 & 0.278165741 \\
-3 & 9 & -0.28183235 & 0.780592384 \\
-3 & 10 & -1.805861544 & 0.084045758 \\
-3 & 11 & -0.392566931 & 0.698253897 \\
\hline
\end{tabular}




\begin{tabular}{llll|}
\hline-3 & 12 & -0.459266569 & 0.650353953 \\
-3 & 13 & -0.774317872 & 0.446630057 \\
-3 & 14 & -0.004422939 & 0.996509156 \\
-3 & 15 & -0.377777273 & 0.70905996 \\
-4 & 1 & -1.919233885 & 0.067445974 \\
-4 & 2 & -1.207345214 & 0.239569252 \\
-4 & 3 & -1.799163575 & 0.085128529 \\
-4 & 4 & -0.715577652 & 0.481454188 \\
-4 & 5 & -1.030551956 & 0.313466937 \\
-4 & -0.481882847 & 0.634442896 \\
-4 & 6 & -1.968099593 & 0.061226467 \\
-4 & 7 & -1.708450861 & 0.101015701 \\
-4 & 8 & -1.095573744 & 0.101015701 \\
-4 & 9 & -2.79131246 & 0.010374966 \\
-4 & 10 & -0.944356633 & 0.354802957 \\
-4 & 11 & -0.929677191 & 0.362193712 \\
-4 & 12 & -0.929677191 & 0.362193712 \\
-4 & 13 & -0.587058406 & 0.562883453 \\
-4 & 13 & -0.968293118 & 0.342970711 \\
\hline
\end{tabular}

In column 3 of above table No: 2, pre-event day -4 and post-event day 10, t-test values and $\mathrm{P}$ values respectively are $\mathrm{t}=-2.79131246$ and $\mathrm{P}=0.010374966$ which are significant. Because its t-test values are higher than 2.00 and its $\mathrm{P}$ value is lower than 0.05. It argues that there is sufficient change in mean of the two populations, which shows that there is impact of terrorist events in Karachi on KSE 100.

Table No: 3

\begin{tabular}{|llll|}
\hline Pre event-days & Post-event days & T-test values & P value two tail test \\
\hline-5 & 1 & -1.388257646 & 0.178359531 \\
-5 & 2 & -0.153597543 & 0.87926678 \\
-5 & 3 & -0.995887356 & 0.329667598 \\
-5 & 4 & 0.165227671 & 0.870208453 \\
-5 & 5 & -0.158462739 & 0.875475312 \\
-5 & 6 & 0.354580943 & 0.726134039 \\
-5 & 7 & -1.328195361 & 0.197143778 \\
-5 & 8 & -1.272379969 & 0.215951697 \\
-5 & 9 & -0.142251094 & 0.888120439 \\
-5 & 10 & -1.695146972 & 0.103545715 \\
-5 & 11 & -0.18750682 & 0.852907614 \\
-5 & 12 & -0.365909521 & 0.717776642 \\
-5 & 13 & -0.606538297 & 0.550097941 \\
-5 & 14 & 0.208829989 & 0.836419393 \\
\hline
\end{tabular}




\begin{tabular}{|llll|}
\hline-5 & 15 & -0.172216939 & 0.86477338 \\
-6 & 1 & -0.461372405 & 0.648865097 \\
-6 & 2 & 0.932086383 & 0.360973732 \\
-6 & 3 & -0.02271438 & 0.982074021 \\
-6 & 4 & 1.029941029 & 0.31374754 \\
-6 & 5 & 0.853300034 & 0.402292409 \\
-6 & 6 & 1.036370413 & 0.310803308 \\
-6 & 7 & -0.346711681 & 0.731960012 \\
-6 & 8 & 0.077332451 & 0.939027885 \\
-6 & 9 & 0.748707645 & 0.461622077 \\
-6 & 10 & -0.648290033 & 0.523217538 \\
-6 & 11 & 0.764897237 & 0.452110203 \\
-6 & 12 & 0.411234089 & 0.684707548 \\
-6 & 13 & 0.29194771 & 0.772943743 \\
-6 & 14 & 1.037032108 & 0.772943743 \\
\hline
\end{tabular}

In the above table No: 3 , we checked that there is no value of $t$ which is greater than 2.00 and same as, no value of $\mathrm{P}$ is lower than 0.005. It means that there is no significantly change between the population means of the above event windows. It indicates that there is no significant change during pre-event day -5 , and -6 and post event days of the terrorist events.

Table No: 4

\begin{tabular}{|llll|}
\hline Pre event-days & Post-event days & T-test values & Pvalue two tail test \\
\hline-7 & 1 & -0.859187036 & 0.399103929 \\
-7 & 2 & 0.375385578 & 0.710813404 \\
-7 & 3 & -0.580482811 & 0.567233594 \\
-7 & 4 & 0.547420548 & 0.58936299 \\
-7 & 5 & 0.299912787 & 0.766937483 \\
-7 & 6 & 0.678891129 & 0.503981596 \\
-7 & 7 & -0.768445734 & 0.450041237 \\
-7 & 8 & -0.435013425 & 0.667607303 \\
-7 & 9 & 0.243252283 & 0.809966381 \\
-7 & 10 & -1.083391977 & 0.289861729 \\
-7 & 11 & 0.266988387 & 0.79185742 \\
-7 & 12 & 0.019985737 & 0.984227122 \\
-7 & 13 & -0.172208083 & 0.864780262 \\
-7 & 14 & 0.628819752 & 0.535662878 \\
-7 & 15 & 0.296548252 & 0.769472796 \\
-8 & 1 & -2.265080213 & $0.033237986 *$ \\
-8 & 2 & -1.628320338 & 0.117079332 \\
\hline
\end{tabular}




\begin{tabular}{|llll|}
\hline-8 & 3 & -2.520292926 & $0.019117591^{*}$ \\
-8 & 4 & -1.302038447 & 0.205792669 \\
-8 & 5 & -1.88027752 & 0.072794563 \\
-8 & 6 & -0.953121681 & 0.350438689 \\
-8 & 6 & -2.664803583 & $0.013838888^{*}$ \\
-8 & 7 & -2.35814376 & $0.027242821^{*}$ \\
-8 & 8 & -1.419807253 & 0.169076883 \\
-8 & 9 & -3.011706958 & $0.006216995^{*}$ \\
-8 & 10 & -1.790955964 & 0.086471717 \\
-8 & 11 & -1.457840429 & 0.158404785 \\
-8 & 12 & -2.959602601 & $0.00702472^{*}$ \\
-8 & 13 & -1.350005424 & 0.190151312 \\
-8 & 14 & -1.76311021 & 0.091165442 \\
\hline
\end{tabular}

In the above table No:4, we examine that pre-event day -8 and post event days 1 , $3,7,8,10$, and $13 \mathrm{t}$ values and $\mathrm{P}$ values are respectively significant ( $\mathrm{t}$ values above than 2.00 and $\mathrm{P}$ values are lower than 0.005). It determines that there is a significant change in the population means of these days. The change in population means indicates that there is a significant change in the return of KSE 100 index. It supports the argument that there is a significant impact of terrorism on KSE 100 and suggested to reject null hypothesis and accept alternative hypothesis.

Table No: 5

\begin{tabular}{|llll|}
\hline Pre event-days & Post-event days & T-test values & P value two tail test \\
\hline-9 & 1 & -1.837009708 & 0.079165273 \\
-9 & 2 & -0.464636276 & 0.646560451 \\
-9 & 3 & -1.596380809 & 0.124053599 \\
-9 & 4 & -0.144154531 & 0.886634111 \\
-9 & 5 & -0.542083968 & 0.592974365 \\
-9 & 6 & 0.054307591 & 0.95715908 \\
-9 & 7 & -1.416686437 & 0.169977546 \\
-9 & 8 & -1.280916684 & 0.212988848 \\
-9 & 9 & -0.386013233 & 0.703034477 \\
-9 & 10 & -2.185099667 & 0.039326687 \\
-9 & 11 & -0.436454633 & 0.666576673 \\
-9 & 12 & -0.600114917 & 0.554296992 \\
-9 & 13 & -1.12268558 & 0.273154403 \\
-9 & 14 & -0.074393131 & 0.941340821 \\
-9 & 15 & -0.396726392 & 0.695226381 \\
-10 & 1 & -1.107659547 & 0.27945865 \\
-10 & 2 & 0.12425177 & 0.902195472 \\
-10 & 3 & -0.913362385 & 0.370527665 \\
-10 & 4 & 0.492477928 & 0.627049913 \\
\hline
\end{tabular}




\begin{tabular}{|llll|}
\hline-10 & 5 & 0.155618909 & 0.877691157 \\
-10 & 6 & 0.530579881 & 0.600795991 \\
-10 & 7 & -0.956643634 & 0.348695313 \\
-10 & 8 & -0.818962411 & 0.421212994 \\
-10 & 9 & 0.080081084 & 0.936865494 \\
-10 & 10 & -1.562557752 & 0.131812395 \\
-10 & 11 & 0.039627814 & 0.968731829 \\
-10 & 12 & -0.16307613 & 0.871882889 \\
-10 & 13 & -0.487499228 & 0.630519016 \\
-10 & 14 & 0.413384741 & $0 a .683153684$ \\
-10 & 15 & 0.050839304 & 0.95989252 \\
\hline
\end{tabular}

Moreover, in the above table No: 5 , there is one row of pre-event day -9 and postevent day 10 has significant values $(t=-2.185099667$ and $P=0.039326687)$. The $t$ value and $P$ values of pre-event day -9 on post-event day 10 are higher than 2.00 and lower than 0.05 respectively. It supports the argument that the populations' means are not equal i.e. $(\mu 1 \neq \mu 2)$.

Table No: 6

\begin{tabular}{|llll|}
\hline Pre event-days & Post-event days & T-test values & Pvalue two tail test \\
\hline-11 & 1 & -0.214069051 & 0.832379658 \\
-11 & 2 & 1.511061318 & 0.144391193 \\
-11 & 3 & 0.616475937 & 0.543634648 \\
-11 & 4 & 2.059651755 & $0.050924768^{*}$ \\
-11 & 5 & 1.430124396 & 0.166126514 \\
-11 & 6 & 1.686862007 & 0.105148246 \\
-11 & 7 & 0.051851613 & 0.959094641 \\
-11 & 8 & 0.553582437 & 0.585206615 \\
-11 & 9 & 1.217855587 & 0.235625756 \\
-11 & 10 & -0.290298887 & 0.774188906 \\
-11 & 11 & 1.253190729 & 0.222727088 \\
-11 & 12 & 0.825630614 & 0.417495709 \\
-11 & 13 & 1.005460842 & 0.325136562 \\
-11 & 14 & 1.532956184 & 0.1389278 \\
-11 & 15 & 1.146578319 & 0.263344726 \\
-12 & 1 & -1.319387881 & 0.200023794 \\
-12 & 2 & 0.009738011 & 0.992314289 \\
-12 & 3 & -0.708511113 & 0.485747508 \\
-12 & 4 & 0.297989359 & 0.76838654 \\
-12 & 5 & 0.036017816 & 0.971578935 \\
-12 & 6 & 0.32489868 & 0.748194542 \\
-12 & 7 & -0.825956719 & 0.417314447 \\
\hline
\end{tabular}




\begin{tabular}{|llll|}
\hline-12 & 8 & -0.668301155 & 0.510593179 \\
-12 & 9 & -0.010529915 & 0.991689303 \\
-12 & 10 & -1.402744659 & 0.174048022 \\
-12 & 11 & -0.048352746 & 0.961852547 \\
-12 & 12 & -0.193074897 & 0.848595133 \\
-12 & 13 & -0.425448809 & 0.674463982 \\
-12 & 14 & 0.259268509 & 0.797734555 \\
-12 & 15 & -0.032613901 & 0.974263863 \\
\hline
\end{tabular}

In above table No: 7 , pre-event day -11 and post-event day $-4 \mathrm{t}$ value and $\mathrm{P}$ value are just significant $(\mathrm{t}=2.059651755, \mathrm{v}=0.050924768)$ and likely to support the argument that population means are not equal. This addresses that our sample data is likely to support the argument that there is impact of terrorist activities on KSE.

Table No: 7

\begin{tabular}{|llll|}
\hline Pre event-days & Post-event days & T-test values & P value two tail test \\
\hline-13 & 1 & -1.732117344 & 0.096644743 \\
-13 & 2 & -0.324465802 & 0.748517953 \\
-13 & 3 & -1.221453551 & 0.234287108 \\
-13 & 4 & -0.029369295 & 0.976823421 \\
-13 & 5 & -0.309821933 & 0.759486083 \\
-13 & 6 & 0.115087685 & 0.909374483 \\
-13 & 7 & -1.182455988 & 0.24910517 \\
-13 & 8 & -1.049170468 & 0.304999745 \\
-13 & 9 & -0.306580923 & 0.761920653 \\
-13 & 10 & -1.91605878 & 0.067868639 \\
-13 & 11 & -0.364945736 & 0.718486269 \\
-13 & 12 & -0.791091016 & 0.646629998 \\
-13 & 13 & -0.464537708 & 0.43697319 \\
-13 & 14 & 0.019320936 & 0.984751718 \\
-13 & 15 & -0.333726562 & 0.741609461 \\
-14 & 1 & -0.580202126 & 0.567419665 \\
-14 & 2 & 0.969526769 & 0.34236826 \\
-14 & 3 & 0.001905635 & 0.998495957 \\
-14 & 3 & 1.23854991 & 0.228004723 \\
-14 & 13 & 1.11132113 & 0.277912775 \\
-14 & 14 & 1.156874105 & 0.259198381 \\
-14 & 4 & -0.343089009 & 0.734647615 \\
-14 & 5 & 0.097735059 & 0.922989413 \\
-14 & 6 & 0.851534016 & 0.403252077 \\
\hline & 7 & -0.786134236 & 0.439813556 \\
\hline
\end{tabular}




\begin{tabular}{|llll|}
\hline-14 & 11 & 0.904402196 & 0.375158333 \\
-14 & 12 & 0.476795392 & 0.638006727 \\
-14 & 13 & 0.453266713 & 0.654604085 \\
-14 & 14 & 1.169431421 & 0.254206783 \\
-14 & 15 & 0.819328596 & 0.421008323 \\
-15 & 1 & -1.014173214 & 0.321050792 \\
-15 & 2 & -0.826728941 & 0.416885414 \\
-15 & 3 & -0.920947473 & 0.366637356 \\
-15 & 4 & -0.794722411 & 0.434899469 \\
-15 & 5 & -0.834566141 & 0.412546907 \\
-15 & 6 & -0.809990455 & 0.426247098 \\
-15 & 7 & -0.936326284 & 0.35883339 \\
-15 & 8 & -0.930160177 & 0.361948914 \\
-15 & 9 & -0.820502803 & 0.420352446 \\
-15 & 10 & -1.00963658 & 0.323173818 \\
-15 & 11 & -0.829164556 & 0.415534045 \\
-15 & 12 & -0.872831752 & 0.391776332 \\
-15 & 13 & -0.887313288 & 0.384095181 \\
-15 & 14 & -0.794798321 & 0.434856185 \\
-15 & 15 & -0.82756936 & 0.416418806 \\
\hline
\end{tabular}

In the above table No 7: we didn't see any significant value of $t$ or P. It indicates that there is no significant change between their population means. It means that in this duration of pre-event window and post-event window of the terrorist events, there is no significant change occurred in the return of the KSE 100. A total of 225 tests, only 11 tests are significant tests which conclude that majority of the events in Karachi didn't affect the return of KSE 100. However, some serious attacks have influence on KSE.

\subsection{One-Way ANOVA}

Table No: 8

\begin{tabular}{|c|c|c|c|c|}
\hline \multicolumn{5}{|c|}{ ANOVA: Single Factor } \\
\hline \multicolumn{5}{|l|}{ Summary } \\
\hline Groups & Count & Sum & Average & Variance \\
\hline Column 1 & 24 & 0.016377232 & 0.000682385 & 9.11397E-05 \\
\hline Column 2 & 24 & -0.005169691 & -0.000215404 & 0.000109399 \\
\hline Column 3 & 24 & 0.040786146 & 0.001699423 & 6.15032E-05 \\
\hline Column 4 & 24 & 0.029987754 & 0.00124949 & 0.000164742 \\
\hline Column 5 & 24 & 0.017056286 & 0.000710679 & 7.51833E-05 \\
\hline Column 6 & 24 & 0.099048453 & 0.004127019 & 5.90898E-05 \\
\hline Column 7 & 24 & 0.014782463 & 0.000615936 & 0.000105268 \\
\hline Column 8 & 24 & 0.056384385 & 0.002349349 & 6.40553E-05 \\
\hline Column 9 & 24 & 0.081067146 & 0.003377798 & 0.000115374 \\
\hline
\end{tabular}




\begin{tabular}{|lllll|}
\hline Column 10 & 24 & -0.012521026 & -0.000521709 & 0.000124509 \\
Column 11 & 24 & 0.011938544 & 0.000497439 & $5.2902 \mathrm{E}-05$ \\
Column 12 & 24 & -0.002435378 & -0.000101474 & $6.17835 \mathrm{E}-05$ \\
Column 13 & 24 & 0.061011848 & 0.00254216 & $6.99852 \mathrm{E}-05$ \\
Column 14 & 24 & 0.013355152 & 0.000556465 & $5.35942 \mathrm{E}-05$ \\
Column 15 & 24 & 0.098168854 & 0.004090369 & 0.000146209 \\
Column 16 & 24 & 0.086702427 & 0.003612601 & $6.33785 \mathrm{E}-05$ \\
Column 17 & 24 & -0.036109003 & -0.001504542 & 0.000101332 \\
Column 18 & 24 & -0.005465446 & -0.000227727 & $7.60979 \mathrm{E}-05$ \\
Column 19 & 24 & -0.047892622 & -0.001995526 & $7.63274 \mathrm{E}-05$ \\
Column 20 & 24 & 0.006386937 & 0.000266122 & $4.25163 \mathrm{E}-05$ \\
Column 21 & 24 & 0.05956259 & 0.002481775 & $7.44131 \mathrm{E}-05$ \\
Column 22 & 24 & 0.031391467 & 0.001307978 & $7.21783 \mathrm{E}-05$ \\
Column 23 & 24 & -0.076230622 & -0.003176276 & $4.09841 \mathrm{E}-05$ \\
Column 24 & 24 & -0.00940984 & -0.000392077 & $3.56253 \mathrm{E}-05$ \\
Column 25 & 24 & 0.019193107 & 0.000799713 & $3.09436 \mathrm{E}-05$ \\
Column 26 & 24 & 0.08444521 & 0.00351855 & $3.03187 \mathrm{E}-05$ \\
Column 27 & 24 & 0.013979988 & 0.0005825 & $9.60903 \mathrm{E}-05$ \\
Column 28 & 24 & -0.003915732 & -0.000163156 & $6.09728 \mathrm{E}-05$ \\
Column 29 & 24 & 0.06110612 & 0.002546088 & $3.24866 \mathrm{E}-05$ \\
Column 30 & 24 & -0.362217702 & -0.015092404 & 0.008557303 \\
\hline
\end{tabular}

ANOVA

\begin{tabular}{|lllllll|}
\hline $\begin{array}{l}\text { Source } \\
\text { of } \\
\text { Variatio } \\
\text { n }\end{array}$ & SS & Df & MS & F & P-value & F crit \\
\hline Between & 0.00821465 & 29 & 0.00028326 & 0.790820 & 0.7765669 & 1.4840026 \\
Groups & 6 & & 4 & 1 & 9 & 1 \\
Within & 0.24715122 & 690 & 0.00035819 & & & \\
Groups & 1 & & & & & \\
Total & 0.25536587 & 719 & & & & \\
\hline
\end{tabular}

Apart from the 225 tests, the study confirmed by One-Way ANOVA test that there is no significant impact of Terrorism in Karachi on KSE 100. The P value of overall t-tests by One-way ANOVA is greater than hypothesized value of 0.05 i.e. $(\mathrm{P}=0.776566991)$. The One-way ANOVA test suggests that there is no significant difference between the mean of the populations which declares that there is no major impact of terrorist activities in Karachi on Karachi stock exchange 100. We accept the 
null hypothesis $(\mu 1=\mu 2)$ and reject alternative hypothesis $(\mu 1 \neq \mu 2)$ and conclude that the estimated population mean and hypothesized population means are equal. However, some of the paints have different means but these are very few as compare to equals means of population.

\section{Conclusion}

The results have shown that there is no major impact of terrorist activities in Karachi by KSE 100 index. However, it is sensitive to some events. Total 27 Terrorist attacks in the period of 2011 to 2014 were selected which were major terrorist activities in Karachi for these 4 years. The result of the research study concludes that Karachi stock exchange is almost insensitive to the terrorist activities in Karachi. However, the attacks which can cause violence throughout the country may have influence on KSE. The result concludes that greater the violence created by the event, more would be its impact on KSE. Attacks on some political leaders cause more adverse effect on KSE as compare to the attack on other civilians. The rescue efforts and the actions of government against terrorism also play their role in minimizing the impact of a terrorist attack on Karachi stock exchange.

As many researchers viewed that KSE has the potential to recover soon after the terrorist event and absorb the effect of the events. Likewise, the KSE was awarded "the best performing stock exchange in the world" in 2002. But then after KSE 100 index declined greatly and closed on 14,127 in December 2007. But after war was declared by the government of Pakistan the index fell to 4,675 points. It showed that Terrorism was the main reason behind the drastic decline of KSE. However, terrorism shows little effect on KSE nowadays, because it serves like a general trend for KSE. Terrorist activities for common civilians in Pakistan and especially for Karachi are like a general trend. It doesn't stop business activities in response to terrorist events and thus shows little effect on KSE. Moreover, mostly investors are domestic, which are well known with country circumstances and they don't feel any fear regarding their investments in Pakistan. They know very well about the fall and down in the economy.

\section{References}

Abbas, F., Ahmed, A., Mahmood, A. \& Hassan, A.(2014). Impact of Terrorism on Karachi Stock Exchange. Pakistan. Journal of Basic and Applied Scientific Research. 4(7)182-191

Ahmed, S., \& Farooq, O. (2008). The effect of 9/11 on the stock market volatility dynamics:Empirical evidence from a front line state. International Research Journal of Finance and Economics, (16), 71-83.

Aslam, F., \& Kang, H. G. (2015). How different terrorist attacks affect stock markets. Defence and Peace Economics, 26(6), 634-648.

Barry Johnston, R., \& Nedelescu, O. M. (2006). The impact of terrorism on financial markets. Journal of Financial Crime, 13(1), 7-25.

Bashir, U., Ul-Haq, I., Gillani, A. H., \& Muhammad, S. (2013). Influence of Terrorist Activities on Financial Markets: Evidence from KSE. Financial Assets and Investing, (2). 
Bilal, A. R., Talib, N. B. A., Haq, I. U., Khan, M. N. A. A., \& Islam, T. (2012). How Terrorism and Macroeconomic Factors Impact on Returns: A Case Study of Karachi Stock Exchange. World Applied Sciences Journal, 19(11), 1575-1584.

Chen, A. H., \& Siems, T. F. (2004). The effects of terrorism on global capital markets. European journal of political economy, 20(2), 349-366.

Chesney, M., Reshetar, G., \& Karaman, M. (2011). The impact of terrorism on financial markets: An empirical study. Journal of Banking \& Finance,35(2), 253-267.

Drakos, K. (2009). Big questions, little answers: Terrorism activity, investor sentiment and stock returns (No. 8). Economics of Security Working Paper.

Gul, T., Hussain, A., Bangash, S., \& Khattak, S. W. (2010). Impact of terrorism on the financial markets of Pakistan. European Journal of Social Sciences, 18(1), 98108.

Hassan, S. A., \& Hashmi, M. S. (2015). Terrorism and the Response of Investors at Capital Market: A Case of Pakistan. Pakistan Journal of Commerce and Social Sciences, 9(1), 218-227.

Hyder, S., Akram, N., \& Padda, I. U. H. (n.a). Impact of terrorism on economic development in pakistan. Pakistan business review, 839.

Karolyi, G. A., \& Martell, R. (2006). Terrorism and the stock market.Available at SSRN 823465.

Kollias, C., Papadamou, S., \& Stagiannis, A. (2011). Terrorism and capital markets: The effects of the Madrid and London bomb attacks. International Review of Economics \& Finance, 20(4), 532-541.

LaFree, G., \& Dugan, L. (2007). Introducing the global terrorism database. Terrorism and Political Violence, 19(2), 181-204.

Nguyen, A. P., \& Enomoto, C. E. (2009). Acts of terrorism and their impacts on stock index returns and volatility: The cases of the Karachi and Tehran stock exchanges. The International Business \& Economics Research Journal, 8(12), 75.

Qaiser, I., Scholar, M. P., Sohail, N., Liaqat, M., \& Mumtaz, A. (n.q). Impact of Terrorism on Forex Market and Karachi Stock Exchange: Evidence from Pakistan.

Suleman, M. T. (2012). Stock market reaction to good and bad political news. Asian Journal of Finance \& Accounting, 4(1), 299-312.

The Impact of Terrorism and Political Events On Stock Market:Empirical Evidence From Pakistan. International Journal of scientific research and management (IJSRM), Vol.3(6),3036-3045. 
